\title{
Prevalence of Short Dental Roots in Four Ethnic Groups in an Orthodontic Population
}

\author{
Kathryn Edgcomb ${ }^{1 *}$, Ellen BeGole ${ }^{1}$, Carla Evans ${ }^{1}$, Bradford Johnson ${ }^{2}$, Xianghong Luan ${ }^{3}$ \\ ${ }^{1}$ Department of Orthodontics, ${ }^{2}$ Department of Endodontics, and ${ }^{3}$ Department of Oral Biology, College of Dentistry, \\ University of Illinois at Chicago
}

ABSTRACT The purpose of the current study was to investigate if a significant relationship exists between ethnicity, sex, and short dental roots. The hypotheses are: 1. Hispanics have a higher prevalence of short dental roots than Caucasians, African Americans, and Asians; and 2. Females have a higher prevalence of short dental roots than males. The experimental groups consisted of 30 Caucasians, 30 Hispanics, 30 African Americans, and 26 Asian subjects who presented to University of Illinois Department of Orthodontics for treatment. Actual root length $(\mathrm{mm})$ and relative root

Root resorption is the most frequent unwanted side-effect of orthodontic treatment discussed with new patients, and occurs in all orthodontic patients to various degrees (Weiland, 2006). The risk of root resorption during treatment has been found to be related to a number of factors, including dental anomalies, syndromes, variations in dental anatomy, sex, mechanics of orthodontic treatment, and disturbances during development, among others. Developmentally short dental roots have been observed to experience a higher incidence of root resorption during orthodontic treatment. Thongudomporn and Freer (1998) found that teeth with one or more dental anomalies, such as invaginations, pipette-shaped roots, or short and blunted roots undergo a significant amount of root resorption during orthodontic treatment as opposed to teeth without these anomalies. Lind (1972) was the first to suggest the connection between developmentally short dental roots and root resorption. He defined short root anomaly as involvement of bilateral maxillary incisors and less commonly canines and premolars. Lind measured the crown-to-root ratios of short-rooted and normal teeth on intraoral radiographs and found that the control group had an average of $5.5 \mathrm{~mm}$ longer maxillary incisor roots than the experimental group. Developmentally short roots have been found in 1.2-10.0\% of pretreatment orthodontic patients (Uslu et al., 2009). These teeth have an unfavorable crown-to-root ratios as compared to teeth with normal root length (Höltta et al., 2004). The ratio of crown-to-root length in these shortened teeth is at least 1.0:1.6 (Desai et al., 2006). Developmentally short length were measured on periapical radiographs, for the maxillary and mandibular central and lateral incisors, and second premolars. The results showed that Asians had the shortest dental root lengths for all teeth measured, except the maxillary second premolar. Significant differences in relative root length values between the ethnic groups were found for the maxillary central incisor and second premolar. Females had shorter roots than their male counterparts within each ethnic group. Dental Anthropology 2011;24 (1):11-15.

roots have been found to be associated with syndromes such as dentin dysplasia, scleroderma, Steven's-Johnson syndrome, Laurence-Moon-Bardet-Biedl syndrome, Thalassemia, Down syndrome, Aarskog syndrome, dwarfism, and Rothmund-Thomson syndrome (Desai et al., 2006). They may also occur simultaneously with other dental anomalies, such as tooth agenesis, dens invaginatus, supernumerary teeth, generalized microdontia, obliterated pulp chambers, increased tooth mobility, and spontaneous exfoliation (Apajalahti et al., 1999). Short dental roots may develop from three mechanisms: disturbances during development, resorption of previously well-formed roots, or genetics. Disturbances during root development can result from radiation or chemotherapy exposure during childhood, or systemic illness such as hypoparathyroidism. Resorption of originally well-formed roots may follow trauma or occur during orthodontic treatment. Short roots may have a genetic origin, such as short root anomaly (Höltta et al., 2004). Teeth with short roots pose difficulties in orthodontic and prosthodontic treatment planning as a result of their unfavorable crown-to-root ratio. Anchorage methods and occlusal loading need to be considered carefully in teeth with short roots (Höltta et al., 2004). The purpose of the current study is to

${ }^{*}$ Correspondence to: Kathryn Edgcomb, Department of Orthodontics, University of Illinois at Chicago, Chicago, IL 60612 USA.

E-mail: kathryn.edgcomb@gmail.com 
investigate the relationship between ethnicity and the prevalence of developmentally short dental roots.

Two hypotheses were tested in this study, namely 1)Hispanics have a statistically significant higher prevalence of developmentally short dental roots than Caucasians, African Americans, and Asians, and 2) females have a higher prevalence of short dental roots than males. If one or more ethnic groups show an increased prevalence of short roots, it may be assumed that they would be at increased risk for root resorption during orthodontic treatment as stated in previous research. This information would be helpful to orthodontists in treatment planning mechanics for their patients.

\section{MATERIALS AND METHODS}

The experimental groups consisted of Caucasians, African Americans, Hispanics, and Asians with 30 subjects in each ethnic group except the Asian group which had 26 subjects due to a lack of cases that met the inclusion criteria for this study. The subjects were at least 14 years of age and both male and female. The subjects' dental records came from the University of Illinois College of Dentistry Orthodontic Clinic patient pool. Subjects satisfied all inclusion criteria, including no history of dental trauma, orthodontics, endodontics, or oral surgery to the teeth being measured. The teeth could not have large caries or restorations of half or more of the crown, significant attrition, significant dilaceration of the root, or be rotated such that their facial and palatal surface were not parallel to the $x$-ray film. Subjects with craniofacial malformations, such as cleft lip and palate, were excluded. All permanent teeth

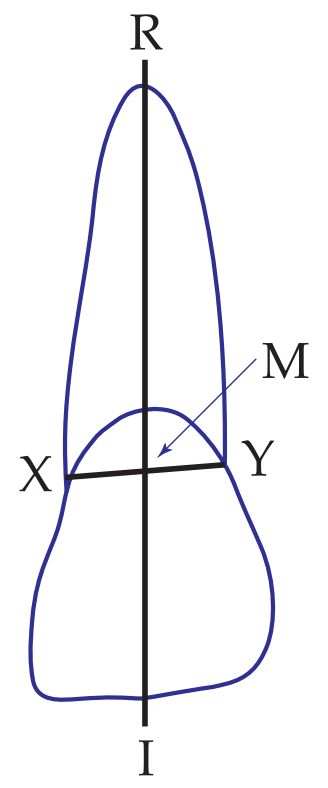

Fig. 1. Reference lines used to measure root length ( $M$ to $\mathrm{R}$ ) and relative root length ( $\mathrm{M}$ to $\mathrm{R}$ divided by I to $\mathrm{M}$ ). were fully erupted, except third molars, and all apices of the teeth were closed. All subjects must have had their pretreatment periapical radiographs taken at the University of Illinois College of Dentistry Radiology clinic between the dates of January 1, 2000, and April 14, 2010.

\section{RADIOGRAPHIC MEASUREMENT TECHNIQUE}

Maxillary and mandibular central and lateral incisors, and second premolar root lengths were measured from the apex to the cervical constriction of the anatomic crown on periapical radiographs. These teeth were chosen because they were single-rooted teeth and their root structures were more clearly identified on radiographs than multi-rooted teeth. As shown in Figure 1 , the $X Y$ line represents the anatomic cementoenamel junction and was found on the radiographs by connecting the mesial and distal cervical constrictions with a line. Point $M$ is defined as the intersection of the $\mathrm{XY}$ line and a straight line connecting the root apex (R) and the midpoint of the incisal edge (I). The length of the root was measured in millimeters from point $\mathrm{M}$ to $R$. The relative root length was measured by dividing the root length (MR) by the crown length (IM) and expressed as a ratio.

The statistical analysis was done using SPSS version 16 (SPSS, Chicago IL). The data measurements gathered were first tested for normality. Two-way analysis of variance tests were done using ethnic group and sex as factors for all teeth measured. P-values of less than or equal to 0.05 were considered statistically significant (two tail). If the overall ANOVA showed significance, Scheffé tests were used to isolate pairwise differences among the means.

\section{RESULTS}

The descriptive statistics for maxillary central incisor root length and relative root length are shown in Table 1. African American males had the longest mean root length $(17.12 \mathrm{~mm})$ and Asian females had the shortest mean root length $(13.73 \mathrm{~mm})$, and this difference between the groups $(\mathrm{F}=3.30, \mathrm{P}=0.02)$ and sexes $(\mathrm{F}=22.0, \mathrm{P}=$ $0.000)$ was statistically significant. Caucasian males had the highest relative root length values (1.66) and Asian females had the smallest (1.40), but this difference was not statistically significant $(\mathrm{F}=2.87, \mathrm{P}=0.09)$.

The descriptive statistics for maxillary lateral incisor root length can be seen in Table 2. A significant difference between sexes was found in the two-way ANOVA, with males having longer mean root length than females by $0.99 \mathrm{~mm}(\mathrm{~F}=8.34, \mathrm{P}=0.005)$. African American males had the longest mean root length $(16.63 \mathrm{~mm})$ and Asian females had the shortest mean root length $(14.67 \mathrm{~mm})$.

The descriptive statistics for the maxillary second 
premolar relative root length are shown in Table 3 . African American males had the highest relative root length value (1.70) and Caucasian males had the lowest (1.61), but this difference was not statistically significant between groups $(\mathrm{F}=0.58, \mathrm{P}=0.63)$ or sexes $(\mathrm{F}=0.02$, $\mathrm{P}=0.88$ ). Caucasian females had relative root length values 0.6 higher than Caucasian males. Hispanic males had a relative root length value 0.3 higher than Hispanic females. African American males had a relative root length value 0.8 higher than African American females. Finally, Asian females had a relative root length value 0.3 higher than Asian males.

The descriptive statistics for the mandibular central incisor are shown in Table 4. Statistically significant differences were found between Caucasians and Asians, and between African Americans and Asians ( $\mathrm{F}=4.46$, $\mathrm{P}=0.005)$. Statistically significant differences were also found between sexes $(\mathrm{F}=4.27, \mathrm{P}=0.04)$. The males in each ethnic group had between $0.21 \mathrm{~mm}$ and $0.77 \mathrm{~mm}$ longer roots than the females within their ethnic group.

The descriptive statistics for the mandibular lateral incisor root length are seen in Table 5. Statistically significant differences were found between Caucasians and Asians, Hispanics and Asians, and African Americans and Asians ( $\mathrm{F}=7.78, \mathrm{P}=0.00)$. The mean root length for Asians was found to be statistically significantly shorter than the other three ethnic groups.

The descriptive statistics for the mandibular second premolar root length are shown in Table 6. Statistically

TABLE 1. Descriptive statistics for the maxillary central incisor

\begin{tabular}{|c|c|c|c|c|c|c|}
\hline Group & Sex & $\begin{array}{l}\text { Mean } \\
\text { root } \\
\text { length }\end{array}$ & sd & $\begin{array}{l}\text { Mean } \\
\text { relative } \\
\text { length }\end{array}$ & sd & $\mathrm{n}$ \\
\hline \multicolumn{7}{|c|}{ Caucasians } \\
\hline & Males & 16.81 & 2.05 & 1.66 & 0.27 & 16 \\
\hline & Females & 14.75 & 1.95 & 1.62 & 0.29 & 14 \\
\hline & Total & 15.85 & 2.23 & 1.64 & 0.27 & 30 \\
\hline \multicolumn{7}{|c|}{ Hispanics } \\
\hline & Males & 15.96 & 2.71 & 1.65 & 0.34 & 11 \\
\hline & Females & 14.55 & 2.38 & 1.61 & 0.21 & 19 \\
\hline & Total & 15.07 & 2.55 & 1.63 & 0.26 & 30 \\
\hline \multicolumn{7}{|c|}{ African Americans } \\
\hline & Males & 17.12 & 1.55 & 1.62 & 0.13 & 16 \\
\hline & Females & 15.21 & 1.76 & 1.52 & 0.24 & 14 \\
\hline & Total & 16.23 & 1.89 & 1.57 & 0.19 & 30 \\
\hline \multicolumn{7}{|c|}{ Asians } \\
\hline & Males & 15.41 & 1.71 & 1.52 & 0.19 & 11 \\
\hline & Females & 13.73 & 1.59 & 1.40 & 0.21 & 15 \\
\hline & Total & 16.23 & 1.82 & 1.45 & 0.21 & 26 \\
\hline \multicolumn{7}{|l|}{ Total } \\
\hline & Males & 16.44 & 2.06 & 1.62 & 0.24 & 54 \\
\hline & Females & 14.55 & 2.00 & 1.54 & 0.25 & 62 \\
\hline & Total & 15.43 & 2.23 & 1.58 & 0.25 & 116 \\
\hline
\end{tabular}

significant differences in mean root length were found between Hispanics and African Americans, and African Americans and Asians, and between sexes in each group $(\mathrm{F}=6.9, \mathrm{P}=0.000)$. Males in each ethnic group had between $0.30 \mathrm{~mm}$ and $0.87 \mathrm{~mm}$ longer roots than the females. The largest difference was found between African American males and females.

\section{DISCUSSION}

The results of the current study indicate that there is a statistically significant relationship between ethnicity and developmentally short dental roots for the maxillary central incisor, mandibular central and lateral incisors, and mandibular second premolars. This finding is in agreement with Lind (1972). Overall, Asians were found to have the shortest roots for all teeth except the maxillary second premolar as compared to Caucasians, Hispanics, and African Americans. Statistically significant differences in relative root length between ethnic groups were found for the maxillary central incisor and second premolar. In the present study, Asians and African American females showed a relative root length value less than 1.6 for the maxillary central incisor which indicates a predisposition to developmentally short dental roots for these teeth as previously stated by Desai et al. (2006). It is possible that Asians and African Americans have tall maxillary central incisor crown heights as compared to their root lengths for this tooth

TABLE 2. Descriptive statistics for the maxillary lateral incisor

\begin{tabular}{ccccc}
\hline Group & Sex & $\begin{array}{c}\text { Mean Root } \\
\text { Length }\end{array}$ & sd & $\mathrm{n}$ \\
\hline
\end{tabular}

Caucasians

Males

Females

16.28

2.15

16

Total

15.04

1.94

14

Hispanics

Males

15.70

2.12

30

Hen

Females

15.86

1.23

11

Total

African Americans

15.34

1.64

19

$1.50 \quad 30$

Males

16.63

1.73

16

Females

15.64

1.90

14

Asians

Total

16.17

1.84

30

Asians

Males

15.64

1.64

11

Females

14.67

1.01

15

Total

15.08

1.38

26

$\begin{array}{lllr}\text { Males } & 16.17 & 1.76 & 54 \\ \text { Females } & 15.18 & 1.65 & 62 \\ \text { Total } & 15.64 & 1.77 & 116\end{array}$


TABLE 3. Descriptive statistics for the maxillary second

\begin{tabular}{|c|c|c|c|c|}
\hline \multicolumn{5}{|c|}{ Mean Root } \\
\hline Group & Sex & Length & $\mathrm{sd}$ & $\mathrm{n}$ \\
\hline \multicolumn{5}{|c|}{ Caucasians } \\
\hline & Males & 1.61 & 0.27 & 16 \\
\hline & Females & 1.67 & 0.31 & 14 \\
\hline & Total & 1.63 & 0.29 & 30 \\
\hline \multicolumn{5}{|c|}{ Hispanics } \\
\hline & Males & 1.68 & 0.23 & 11 \\
\hline & Females & 1.71 & 0.29 & 19 \\
\hline & Total & 1.70 & 0.27 & 30 \\
\hline \multicolumn{5}{|c|}{ African Americans } \\
\hline & Males & 1.79 & 0.52 & 16 \\
\hline & Females & 1.71 & 0.25 & 14 \\
\hline & Total & 1.75 & 0.41 & 30 \\
\hline \multicolumn{5}{|l|}{ Asians } \\
\hline & Males & 1.70 & 0.37 & 11 \\
\hline & Females & 1.73 & 0.39 & 15 \\
\hline & Total & 1.72 & 0.37 & 26 \\
\hline \multicolumn{5}{|l|}{ Total } \\
\hline & Males & 1.70 & 0.37 & 54 \\
\hline & Females & 1.70 & 0.31 & 62 \\
\hline & Total & 1.70 & 0.34 & 116 \\
\hline
\end{tabular}

TABLE 4. Descriptive statistics for the mandibular central incisor

\begin{tabular}{|c|c|c|c|c|}
\hline \multicolumn{5}{|c|}{ Mean Root } \\
\hline Group & Sex & Length & $\mathrm{sd}$ & $\mathrm{n}$ \\
\hline \multicolumn{5}{|c|}{ Caucasians } \\
\hline & Males & 14.84 & 1.33 & 16 \\
\hline & Females & 14.07 & 1.09 & 14 \\
\hline & Total & 14.48 & 1.26 & 30 \\
\hline \multicolumn{5}{|l|}{ Hispanics } \\
\hline & Males & 14.18 & 2.04 & 11 \\
\hline & Females & 13.50 & 1.47 & 19 \\
\hline & Total & 13.75 & 1.70 & 30 \\
\hline \multicolumn{5}{|c|}{ African Americans } \\
\hline & Males & 14.25 & 1.99 & 16 \\
\hline & Females & 14.04 & 1.43 & 14 \\
\hline & Total & 14.15 & 1.73 & 30 \\
\hline Asidnis & Males & 13.36 & 1.83 & 11 \\
\hline & Females & 12.60 & 1.21 & 15 \\
\hline & Total & 12.92 & 1.52 & 26 \\
\hline \multicolumn{5}{|l|}{ Total } \\
\hline & Females & 13.53 & 1.42 & 62 \\
\hline & Total & 13.86 & 1.65 & 116 \\
\hline
\end{tabular}

TABLE 5. Descriptive statistics for the mandibular lateral incisor

\begin{tabular}{llccc}
\hline Group & Sex & $\begin{array}{c}\text { Mean Root } \\
\text { Length }\end{array}$ & sd & $\mathrm{n}$ \\
\hline Caucasians & & & & \\
& Males & 15.22 & 1.99 & 16 \\
& Females & 15.50 & 1.53 & 14 \\
& Total & 15.35 & 1.77 & 30 \\
Hispanics & & & & \\
& Males & 15.64 & 1.58 & 11 \\
& Females & 14.68 & 1.60 & 19 \\
African Americans & 15.03 & 1.63 & 30 \\
& Total & & & \\
& Males & 15.84 & 1.50 & 16 \\
& Females & 15.64 & 1.57 & 14 \\
Asians & Total & 15.75 & 1.51 & 30 \\
& Males & 13.91 & 1.55 & 11 \\
& Females & 13.67 & 1.11 & 15 \\
\multirow{5}{*}{ Total } & Total & 13.77 & 1.29 & 26 \\
& & & & \\
& Males & 15.22 & 1.79 & 54 \\
& Females & 14.84 & 1.63 & 62 \\
& Total & 15.02 & 1.71 & 116 \\
\hline
\end{tabular}

TABLE 6. Descriptive statistics for the mandibular second premolar

\begin{tabular}{|c|c|c|c|c|}
\hline & & Mean Roc & & \\
\hline Group & Sex & Length & sd & $\mathrm{n}$ \\
\hline Caucasiar & & & & \\
\hline & Males & 15.59 & 2.10 & 16 \\
\hline & Females & 15.29 & 2.53 & 14 \\
\hline & Total & 15.45 & 2.28 & 30 \\
\hline Hispanics & & & & \\
\hline & Males & 14.73 & 1.03 & 11 \\
\hline & Females & 14.42 & 1.59 & 19 \\
\hline & Total & 14.53 & 1.40 & 30 \\
\hline African A & nericans & & & \\
\hline & Males & 16.94 & 2.50 & 16 \\
\hline & Females & 16.07 & 1.81 & 14 \\
\hline & Total & 16.53 & 2.21 & 30 \\
\hline Asians & & & & \\
\hline & Males & 14.73 & 1.69 & 11 \\
\hline & Females & 14.13 & 1.64 & 15 \\
\hline & Total & 14.39 & 1.66 & 26 \\
\hline Total & & & & \\
\hline & Males & 15.64 & 2.15 & 54 \\
\hline & Females & 14.92 & 2.00 & 62 \\
\hline & Total & 15.25 & 2.09 & 116 \\
\hline
\end{tabular}


and results in smaller relative root length values. Asians may be particularly vulnerable to developmentally short maxillary incisor roots because they also had the shortest mean root length for this tooth. All four ethnic groups had relative root length values greater than 1.6 for the maxillary second premolar which indicates that this tooth does not appear to be predisposed to being developmentally short.

Statistically significant differences in mean root length were found between sexes for the maxillary central and lateral incisors, mandibular central incisors and second premolars. Furthermore, statistically significant differences were found for relative root length values between sexes for the maxillary central incisors. In the majority of teeth, females had shorter roots than their male counterparts within their ethnic group. This finding was in agreement with Kjaer (1995) and Lind (1972).

There were several limitations to the current study. First, the mesial and distal cervical constrictions and the apices of the teeth were not always clear on the radiographs. This could have introduced measurement error into the results. A second limitation was that although the periapical radiographs were taken using the long cone paralleling technique they were taken by different operators and some magnification, elongation, or foreshortening distortions could have been introduced into the images due to operator variability. However, according to Sameshima and Asgarifar (2001) the magnification factor associated with periapical films is less than $5 \%$, and intraoral films are accurate within $0.3 \mathrm{~mm}$. A third limitation of the current study is that it could not be confirmed that the subjects were not of mixed ethnic background. The ethnicity of the subjects was identified from their electronic record. A more accurate way to ensure that the subjects were of a homogenous ethnic background would be to question family members, but this was not realistic since the current study was retrospective in nature.

\section{CONCLUSIONS}

The current study found that Asians had the shortest dental root lengths for all teeth measured, except for the maxillary second premolar, as compared to Caucasians, Hispanics, and African Americans. Statistically significant differences in root length were found between ethnic groups for the maxillary central incisor, mandibular central and lateral incisors, and mandibular second premolar. Significant differences in relative root length values among the ethnic groups were found for the maxillary central incisors. Statistically significant differences between sexes were found for the maxillary central and lateral incisors, and the mandibular central incisor mean root lengths, plus the maxillary central incisor relative root lengths. Females had shorter roots than their male counterparts within each ethnic group for the teeth measured.

\section{LITERATURE CITED}

Apajalahti S, Arte S, Pirinen S. 1999. Short root anomaly in families and its association with other dental anomalies. Eur J Oral Sci 107:97-101.

Desai R, Vanaki S, Puranik R, Rashmi G, Nidawami P. 2006. A combination of idiopathic generalized short-root anomaly associated with microdontia, taurodontia, multiple dens invaginatus, obliterated pulp chambers, and infected cyst: a case report. J Oral Pathol Med 35:407-409.

Höltta P, Nystrom M, Evalahti M, and Alaluusua S. 2004. Root-crown ratios of permanent teeth in a healthy Finnish population assessed from panoramic radiographs. Eur J Orthod 26:491-497.

Kjaer I. 1995. Morphological characteristics of dentitions developing excessive root resorption during orthodontic treatment. Eur J Orthod 17:25-34.

Lind V. 1972. Short root anomaly. Scand J Dent Res 80:85-93.

Sameshima G, Asgarifar K. 2001. Assessment of root resorption and root shape: periapical vs panoramic films. Angle Orthod 71:185-189.

Thongudomporn U, Freer T. 1998. Prevalence of dental anomalies in orthodontic patients. Aust Dent J 43:395-398.

Uslu O, Akcam OM, Evirgen S, Cebeci L. 2009. Prevalence of dental anomalies in various malocclusions. Am J Orthod Dentofacial Orthop 135:328-335.

Weiland F. 2006. External root resorptions and orthodontic forces: correlations and clinical consequences. Prog Orthod 7:156-163. 